\title{
Supervision as therapy
}

\section{John Launer}

For most of the week I have a job in postgraduate medical education, helping hospital doctors and general practitioners to become better supervisors. However, for some of the week, I also work in a mental health clinic where I see children and families with emotional difficulties. I teach and supervise trainees there myself-not just psychiatrists, but also psychologists and therapists of various kinds. During the course of an average working week in these two jobs I probably mention the word 'supervision' a hundred times at least.

I am always conscious that the word has different meanings according to where I $\mathrm{am}$, and who I am talking to. In the postgraduate medical context, for example, it is nearly always taken to mean some kind of instruction. In the mental health world, by contrast, people regard supervision as a very different kind of conversation. Although instruction may play a part in it, that is rarely its main focus. Instead, supervision is seen as more of a dialogue where both parties are trying to develop a shared understanding of what is going on. In doing so, they are also trying to enhance their understanding of themselves, their own reactions, and their assumptions.

In many ways, the understanding that mental health professionals have of supervision is not entirely different from the one they have of therapy itself. And while supervision and therapy clearly aren't the same thing, and need to be distinguished clearly from one another, most mental health professionals would recognise that they share many of the same features. These include a certain kind of reflective attitude, and creating opportunities for gradual or sudden new insights to emerge.

These two kinds of supervisionmedical and therapeutic - can seem at first sight to be so radically different from each other that one might as well use entirely different words for them. Indeed, I come across doctors and therapists who accuse each other of using the word incorrectly.

Correspondence to Dr John Launer, London Deanery, Stewart House, London WC1B 5DN, UK;

jlauner@londondeanery.ac.uk
"What's the point of supervision," doctors sometimes ask, "if you don't actually tell people what to do?" And the therapists retort by saying "What kind of supervision is it, if you just take over the conversation and don't allow someone to develop their own ideas at their own pace?"

However, once you get the prejudices and semantic squabbles out of the way, both sides recognise that there is much to be said for both constructions of the word. Therapists can concede that in a technical field like medicine you sometimes have to tell a trainee what is best for the patient. The doctors, on a good day, will concede that supervision in medicine could be just a little less dogmatic and hierarchical than it often is. It might even be regarded occasionally as just a tiny bit therapeutic.

\section{CHANGING CULTURE}

The culture of supervision in medicine is now changing, possibly more rapidly than ever before. Supervision of doctors is becoming less haphazard and more professional in many countries. Clinical teachers are actually getting trained in how to do good supervision. Trainees are finding themselves on ward rounds, and in clinics or seminar rooms, with teachers who have chosen to be educators rather than simply doing it because it was on the list of their duties, somewhere below clinical work, research and management. It isn't shocking any more to suggest that knowing how to do the job doesn't equate automatically with being able to teach it. It doesn't seem so provocative to say that supervision needs protected time, a considered attitude, and a specific set of interactional skills.

Now that we have come so far, I wonder if we should be even bolder as a profession and start to use the 'Tword' explicitly. Why shouldn't we conceptualise supervision in medicine as primarily therapeutic in its purpose-not just for the supervisee, but also for the supervisor, and hopefully for the patients?

Let me emphasise at once that I'm not suggesting supervisors should behave like therapists in crass and inappropriate ways-for example, by exploring personal aspects of their trainee's lives, making interpretations, or behaving like cartoon psychoanalysts. What I propose instead is that we should recognise that good supervision in medicine, as in the mental health field, includes openness to more than just factual learning. It involves opening oneself to uncertainty, anxiety, curiosity, multiple perspectives, and the constant possibility that one might be getting things drastically wrong as well as miraculously right.

\section{INVITATION TO OPENNESS}

This invitation to openness in all its facets applies just as much to the person doing the supervising as it does to the person being supervised. It makes supervision an enterprise where the expansion of knowledge and wisdom is intertwined and mutual.

If this seems like pie in the sky, try to recall some moments of supervision in the recent or distant past that have had the most impact on you. Almost certainly, they went far beyond somebody just telling you the right answer: what test to do, what the diagnosis was, or what treatment to give. Far more likely, these were moments of conversation where your supervisors showed something personal of themselves-an emotional engagement, a moral depth-and also paid respect to you as an equal.

Possibly, the effect of what they said wasn't just in the content, but in their manner too. You may have been struck by their willingness to match their contributions to your own level of understanding, or by the way they modelled how to think, speak, and behave as a professional. You might even be able to recall moments like this where more than one person was affected as a result: not just your supervisor and yourself, but other colleagues around you, and of course patients too.

There is a word for such encounters, and for the way they seem to reverberate through many dimensions and touch many people directly or indirectly. That word is 'therapeutic'.

\section{Competing interests None.}

Provenance and peer review Commissioned; not externally peer reviewed.

Published Online First 10 October 2010

Postgrad Med J 2010;86:686

doi:10.1136/pgmj.2010.109942 